\title{
IMUNIDADE CRUZADA PELAS SEMENTES DE Abrus precatorius E Ricinus communis EM BOVINOS ${ }^{1}$
}

\author{
Carlos Hubinger Tokarnia² e Jürgen Döbereiner ${ }^{3}$
}

\begin{abstract}
Tokarnia C.H. \& Dobereiner J. 1997. [Cross-immunity by the seeds of Abrus precatorius and Ricinus communis in cattle.] Imunidade cruzada pelas sementes de Abrus precatorius e Ricinus communis em bovinos. Pesquisa Veterinária Brasileira 17(1): 25-35. Projeto Saúde Animal Embrapa /UFRRJ, Km 47, Seropédica, RJ 23851-970, Brazil.

Five bovines immunized against the toxicity of the seeds of Abrus precatorius $\mathrm{L}$. (jequiriti bean) did not get poisoned or only slightly so when the seeds of Ricinus communis L. (castor bean) were given in amounts that in bovines, which never before ingested the seeds of $A$. precatorius or $R$. communis, caused moderate to severe poisoning or even death. A sixth bovine, which was not well immunized against the toxic action of the seeds of $A$. precatorius, was severely poisoned when given a high dose of the seeds of $R$. communis. On the other side, from five bovines immunized against the toxic action of the seeds of $R$. communis four were severely poisoned and the fifth one moderately when the seeds of $A$. precatorius were given in doses that in bovines, which never before ingested seeds of $R$. communis or A. precatorius, caused slight to severe poisoning. It is concluded that bovines immunized against the toxic action of the seeds of $A$. precatorius are resistant to the toxic action of the seeds of $R$. communis, but that the contrary is not the case; this is, bovines immunized against the toxic action of the seeds of $R$. communis were not protected against the poisoning by A. precatorius.

Earlier studies by other authors had shown that the toxalbumins of the seeds of $A$. precatorius and $R$. communis, respectively abrin and ricin, are different as to their antigenic properties. A possible explanation for the difference in results can be.that in the present study polygastric animals were used which received the seeds orally, but in the earlier studies monogastric animals received the seeds or toxins by parenteral route.

The administration of the fresh leaves or the pericarp of the fruits $R$. communis to bovines, which had been immunized against the action of the seeds of the plant, had the same toxic effect as to not immunized animals, showing that the immunity due to ricin does not give protection against the action of ricinin, the toxic principle of the leaves and the pericarp.
\end{abstract}

INDEX TERMS: Abrus precatorius, Ricinus communis, seeds, cross-immunity, cattle.

SINOPSE.- Cinco bovinos imunizados contra a ação tóxica das sementes de Abrus precatorius L. ("tento", "jiquiriti") não adoeceram ou somente levemente pela administração das sementes de Ricinus communis L. ("mamona"), em doses que em bovinos que antes nunca ingeriram sementes de $A$. precatorius

\footnotetext{
${ }^{1}$ Aceito para publicação em 8 de janeiro de 1997.

2 Depto Nutrição Animal e Pastagem, Universidade Federal Rural do Rio de Janeiro (UFRRJ), Km 47, Seropédica, RJ 23851 970; bolsista do CNPq (305010/ 76-VT).

3 Projeto Saúde Animal Embrapa/UFRRJ, Km 47, Seropédica, Rio de Janeiro 23851-970; bolsista do CNPq (305294/88-1).
}

ou R. communis, causaram intoxicação de intensidade de grau moderado a acentuado ou até a morte. Um sexto bovino, que não ficou bem imunizado contra a ação tóxica das sementes de $A$. precatorius, adoeceu em grau acentuado pela administração de dose elevada das sementes de $R$. communis. Já dos cinco bovinos imunizados contra a ação tóxica das sementes de $R$. communis quatro adoeceram em grau acentuado, oquinto em grau moderado, pela administração das sementes de $A$. precatorias em doses que em bovinos que antes nunca ingeriram sementes de $R$. communis ou $A$. precatorius causaram intoxicação de intensidade leve a acentuada. Estes resultados permitem concluir que bovinos imunizados contra a ação tóxica das sementes de $A$. precatorius são resisten- 
tes à ação tóxica das sementes de $R$. communis, mas que o contrário não ocorre, isto é, bovinos imunizados contra a ação tóxica das sementes de $R$. communis, não se mostraram protegidos contra a intoxicação por A. precatorius.

Estudos anteriores por outros autores mostraram que as toxalbuminas de $A$. precatorius e $R$. communis, respectivamente abrina e ricina, são diferentes do ponto de vista antigênico. Uma explicação para a divergência desses resultados com os nossos poderia estar no fato de que no presente estudo foram usados poligástricos que receberam as sementes por via oral, enquanto que nos estudos anteriores foram usados monogástricos em que as sementes ou as toxinas foram aplicadas por via parenteral.

A administração de folhas frescas ou do pericarpo do fruto de $R$. communis a bovinos imunizados contra a ação das sementes desta planta tiveram o mesmo efeito tóxico que em animais não imunizados, demonstrando que a imunidade conferida pela ricina não inibe a ação da ricinina, o principio tóxico das folhas e do pericarpo.

TERMOS DE INDEXAÇAO: Abrus precatorius, Ricinus communis, sementes, imunidade cruzada, bovinos.

\section{INTRODUÇAO}

Os principios tóxicos das sementes de Abrus precatorius L. ("tento", "jiquiriti"), a abrina, e de Ricinus communis L. ("mamona"), a ricina, tem propriedades muito semelhantes. Ambos são proteínas e pela administração oral provocam gastrenterite. Pela administração sucessiva de doses subletais, a intervalos, por qualquer via, os animais podem ser imunizados contra a ação tóxica dessas substancias. Porém estas duas proteínas, de acordo com Clarke \& Humphreys (1971) citando Ehrlich (1891), podem ser distinguidas pela sua antigenicidade, um animal imunizado contra abrina não teria proteção contra ricina e vice-versa.

Ehrlich (1891) diz que investigou detalhadamente as imunidades de ricina e de abrina e que podia afirmar com segurança, que não há qualquer reciprocidade imunológica entre elas. Diz que animais imunes contra ricina são tão sensíveis contra abrina, como animais normais, da mesma maneira como animais imunes contra abrina o são contra ricina. Descreve somente um experimento: um coelho, pela instilação diária de ricina no olho chegou ao ponto de diariamente suportar qualquer quantidade de ricina colocada sob forma de pó na conjuntiva, mas adoeceu imediatamente com uma inflamação forte quando uma solução de abrina diluída a 1:10000 foi instilado no olho. Conclui que não poderia haver uma prova mais contundente, de que a antiabrina e a antiricina não tenham qualquer relação entre si.

Por sua vez, Clarke \& Humphreys (1971) repetiram, através de um experimento em ratos, o trabalho de Ehrlich (1891) sobre a especificidade da imunidade conferida pela inoculação prévia de sucessivas pequenas quantidades de abrina e ricina. Dois grupos, cada um composto por seis ratos, foram imunizados. Grupo A recebeu inoculações intraperitoniais sucessivas de $1 \mathrm{mg}, 5 \mathrm{mg}$ e $10 \mathrm{mg}$ de abrina com intervalos de uma semana entre si. Grupo B recebeu incoculações semelhantes de ricina. Após um intervalo de 10 dias, a metade dos ratos de cada grupo recebeu uma inoculação intraperitoneal de $\mathbf{2 0}$ , mg de abrina, a outra metade recebeu inoculação semelhante de ricina. Dos ratos injetados com abrina, os três imunizados com essa substancia, sobreviveram, porém aqueles imunizados com ricina, morreram em aproximadamente 48 horas, como também os controles não imunizados. De maneira semelhante, somente os ratos imunizados com ricina sobreviveram à injeção com este composto. Estes autores então concluem, que este experimento confirma definitivamente que a imunização contra uma das fitotoxinas não confere qualquer imunidade contra a outra.

As folhas e o pericarpo do fruto de $R$. communis também são tóxicos, porém o princípio tóxico destas partes é um alcalóide, denominado ricinina. $\mathrm{O}$ quadro clinico-patológico produzido pela ingestão das folhas ou do pericarpo é bem diferente daquele provocado pelas sementes, pois é de ordem nervosa. (Tokarnia et al. 1975, Döbereiner et al. 1981)

0 presente trabalho foi realizado para verificar se bovinos imunizados pela administração por via oral das sementes de $A$. precatorius são imunes contra a intoxicação pelas sementes de $R$. communis e se bovinos imunizados pela administração por via oral das sementes de $R$. communis são imunes contra a intoxicação pelas sementes de $A$. precatorius. Aproveitou-se os animais imunizados contra a ação tóxica das sementes de $R$. communis para verificar se tinham alguma resistência contra a intoxicação pelas folhas e o pericarpo do fruto de $R$. communis.

\section{MATERIAL E MÉTODOS}

Em todos os experimentos foram usadas as sementes maduras tanto de Abrus precatorius L. (Leg. Papilionoideae) como de Ricinus communis L. (Euphorbiaceae). Todas as administrações foram feitas por via oral. Na maioria dos experimentos as sementes, inteiras ou trituradas, foram dadas misturadas com a ração; em alguns experimentos as sementes inteiras ou trituradas foram dadas por sonda esofagiana.

Os bovinos utilizados eram animais jovens com idade variando entre 1 e 2 anos e nunca antes ingeriram sementes de $A$. precatorins e $R$. communis.

Esse trabalho experimental se compõe de quatro partes:

Parte 1: Imunização de bovinos através da administração das sementes inteiras de $A$. precatorius e posterior administração de dose elevada única das sementes inteiras de R. communis.

Parte 2: Imunização de bovinos através da administração das sementes inteiras de $R$. communis e posterior administração de dose elevada única das sementes inteiras de $A$. precatorius.

Parte 3: Imunização de bovinos através da administração das sementes moídas de A. precatorius e posterior administração de dose elevada única das sementes esmagadas de $R$. communis.

Parte 4: Imunização de bovinos através da administração das sementes esmagadas de $R$. communis e posterior administração de dose elevada única das sementes moídas de $A$. precatorius. Posteriormente, esses mesmos bovinos receberam dose elevada única das folhas sem o talo de $R$. commnis e mais tarde receberam dose elevada única do pericarpo da mesma planta.

Os experimentos relativos às Partes 1 e 2 foram realizados no período de 1967 a 1969. Os dados dos experimentos 
relativos à Parte 1 já constam em trabalho publicado anteriormente (Tokarnia et al. 1970), porém foram incorporados aqui e são apresentados de outra maneira, para facilitar a sua interpretação e discussão neste outro contexto. Os experimentos relativos às Partes 3 e 4 foram realizados em 1974.

Os detalhes em relação a cada uma dessas Partes são as seguintes:

Parte 1: Três bovinos receberam as sementes inteiras de $A$. precatorius repetidas vezes. $O$ primeiro bovino recebeu 4 vezes a dose de $1 \mathrm{~g} / \mathrm{kg}$ num período de aproximadamente 13 meses, o segundo recebeu 4 vezes a dose de $0,1 \mathrm{~g} / \mathrm{kg}$ num período de 3 meses, e numa $5^{\text {a }}$ administração, a dose de $1 \mathrm{~g} / \mathrm{kg}$ depois de 1 mês, e o terceiro bovino recebeu 3 vezes a dose de $0,11 \mathrm{~g} / \mathrm{kg}$ num período de 2 meses, e, numa $4^{\text {a }}$ administração, cerca de 1 mês depois, a dose de 1,1 $\mathrm{g} / \mathrm{kg}$. Aproximadamente 1 mês após a última administração das sementes de $A$. precatorius os três bovinos receberam por via oral a dose única de 1,85 ou $2 \mathrm{~g} / \mathrm{kg}$ das sementes inteiras de $R$. communis.

Parte 2: Três bovinos receberam as sementes inteiras de $R$. communis, respectivamente nas doses de $1 \mathrm{~g} / \mathrm{kg}, 2 \mathrm{~g} / \mathrm{kg}$ e $2,91 \mathrm{~g} / \mathrm{kg}$. Os primeiros dois bovinos receberam, com intervalos de aproximadamente 1 mês cada um, mais duas doses de $2 \mathrm{~g} / \mathrm{kg}$ das sementes inteiras de $R$. communis. Após mais um intervalo de aproximadamente 1 mês, esses dois bovinos receberam (sempre por via oral) as sementes inteiras de $A$. precatorius nas doses de 0,93 ou $1 \mathrm{~g} / \mathrm{kg}$. O bovino que ingeriu inicialmente a dose de $2,91 \mathrm{~g} / \mathrm{kg}$ das sementes de $R$. communis morreu com essa dose.

Parte 3: Três bovinos receberam as sementes moídas de $A$. precatorius repetidamente, sempre com intervalos de 4 semanas entre as administrações em doses crescentes, sempre inicialmente na dose de $0,25 \mathrm{~g} / \mathrm{kg}$, na segunda administração na dose de 0,25 ou 0,5 $\mathrm{g} / \mathrm{kg}$, nas terceiras e quartas administrações na dose de $1 \mathrm{~g} / \mathrm{kg}$. Novamente com intervalo de 4 semanas receberam (sempre por via oral) as sementes esmagadas de $R$. communis na dose de $6 \mathrm{~g} / \mathrm{kg}$.

Parte 4: Três bovinos receberam as sementes esmagadas de $R$. communis, repetidamente, sempre com intervalos de 4 semanas entre as administrações, em doses crescentes; o primeiro bovino recebeu como primeira dose $1 \mathrm{~g} / \mathrm{kg}$, o segundo $2 \mathrm{~g} / \mathrm{kg}$ e o terceiro $3 \mathrm{~g} / \mathrm{kg}$ das sementes esmagadas de $R$. communis. Um quarto bovino, que recebeu $a$ dose única de $6 \mathrm{~g} / \mathrm{kg}$, morreu após a primeira administração. Na segunda administração os três primeiros bovinos receberam doses de 3 ou $5 \mathrm{~g} / \mathrm{kg}$, nas 3as e 4as administrações cada vez $6 \mathrm{~g} / \mathrm{kg}$ das sementes esmagadas de $R$. communis. Na 5 a ad $\mathrm{m}$ i n istração em vez das sementes de $R$. com munis era $\mathrm{m}$ administradas as sementes moídas de A. precatorius, sempre na dose de $1 \mathrm{~g} / \mathrm{kg}$. Esses mesmos bovinos receberam depois de 3 a 4 semanas dose única elevada das folhas sem talo, e, após mais 2 semanas, dose única elevada do pericarpo dos frutos de $R$. communis.

Durante os experimentos os animais eram examinados diariamente, com tomada de temperatura, auscultação do coração e do pulmão, bem como do rúmen, no período de 1967 a 1969, na parte da manhã, nos experimentos realizados em 1974, na parte da manhã e uma segunda vez na parte da tarde. Diversas vezes por dia os animais eram observados, especialmente em relação ao apetite e o aspecto das fezes. Nos casos de morte, se fazia imediatamente a necropsia, com coleta de material para exames histopatológicos. Este material era processado rotineiramente.

A procedência e período de coleta das sementes de $A$. precatorius e $R$. communis, bem como do pericarpo e das fo- lhas frescas de R.communis usados nos experimentos, foram os seguintes:

Parte 1: Sementes de A. precatorius coletadas na Fazenda Indiana, Campo Grande, RJ, no período de 1967/68. Sementes de $R$. communis coletadas na área do Km 47, Seropédica, RJ, em 1968.

Parte 2: Sementes de R. communis coletadas na área do $\mathrm{Km} 47$, Seropédica, RJ, em 1968. Sementes de $A$. precatorius coletadas na Fazenda Indiana, Campo Grande, RJ, em 1968.

Parte 3: Sementes de A. precatorius coletadas na área do $\mathrm{Km} 47$, Seropédica, RJ, em 1973. Sementes de $R$. communis coletadas no município de Barra do Pirai, RJ, em 1974.

Parte 4: Sementes de $R$. communis e pericarpo coletados no município de Barra do Pirai, RJ, em 1974. Folhas de R. communis coletadas na Mazombinha, município de Itaguaí, RJ, nos dias dos experimentos. Sementes de $A$. precatorius coletadas na área do $\mathrm{Km} \mathrm{47,}$ Seropédica, RJ, no período de 1972/73

\section{RESULTADOS}

O delineamento experimental e os principais resultados em relação aos quadros clínicos constam nos Quadros 1 a 4. Pela leitura dos Quadros verifica-se:

1) Em relação aos bovinos imunizados pela administração repetida das sementes de Abrus precatorius

Parte 1: Três bovinos imunizados pela administração repetida das sementes inteiras de $A$. precatorius, não adoeceram pela administração das sementes inteiras de $R$. communis, em doses de 1,85 e $2 \mathrm{~g} / \mathrm{kg}$, sendo que a dose de $2 \mathrm{~g} / \mathrm{kg}$ causou intoxicação de intensidade acentuada em bovino que antes nunca ingeriu sementes de $A$. precatorius ou $R$. communis (Quadro 5 ).

Parte 3: Dois bovinos imunizados pela administração repetida das sementes moídas de $A$. precatorius, só adoeceram levemente pela administração das sementes esmagadas de $R$. communis, na dose de $6 \mathrm{~g} / \mathrm{kg}$, dose que causou a morte de bovino que antes nunca ingeriu as sementes de $A$. precatorius ou $R$. communis (Quadro 5 ). Um bovino que, ao contrário dos outros, não se conseguiu imunizar pela administração das sementes moídas de $A$. precatorius, adoeceu em grau acentuado pela administração das sementes esmagadas de $R$. communis, também na dose de $6 \mathrm{~g} / \mathrm{kg}$.

2) Em relação aos bovinos imunizados pela administração repetida das sementes de Ricinus communis

Parte 2: De dois bovinos imunizados pela administração repetida das sementes inteiras de $R$. communis, um adoeceu em grau acentuado, o outro em grau moderado, pela administração das sementes inteiras de $A$. precatorius, nas doses de 0,93 e $1,06 \mathrm{~g} / \mathrm{kg}$ (sementes inteiras), doses que em bovinos que antes nunca ingeriram sementes de $R$. communis ou $A$. precatorius, causaram intoxicação leve a acentuada (Quadro 5).

Parte 4: Três bovinos imunizados pela administração repetida das sementes esmagadas de $R$. communis, adoeceram em grau acentuado pela administração das sementes moídas de $A$. precatorius, na dose de $1 \mathrm{~g} / \mathrm{kg}$, sendo que doses de 0,25 e $0,5 \mathrm{~g} / \mathrm{kg}$ (sementes moídas) causaram intoxicação de grau moderado a acentuado e dose de $0,61 \mathrm{~g} / \mathrm{kg}$ (sementes moídas) (por sonda) a morte em bovinos que antes nunca ingeriram as sementes de $R$. communis ou $A$. precatorius (Quadro 5).

Os bovinos imunizados pela administração das sementes esmagadas de $R$. communis e recuperados pelo desafio de $A$. precatorius, não mostraram resistência à intoxicação pelas folhas sem talo ou o pericarpo dos frutos de $R$. communis. 
Quadro 1. Imunização de bovinos através da administração das sementes inteiras de Abrus precatorius e posterior administração de dose elevada única das sementes inteiras de Ricinus communis (Resumo dos experimentos da Parte 1)

\begin{tabular}{|c|c|c|c|c|c|c|c|c|c|c|c|}
\hline Sementes & Bovino & Peso & Data & Qu & lade & $\begin{array}{c}\text { Dose } \\
\mathrm{g} / \mathrm{kg} \\
\text { Elimina- } \\
\text { da nas } \\
\text { fezes }\end{array}$ & Desfecho & $\begin{array}{l}\text { Início dos } \\
\text { sintomas } \\
\text { após admi- } \\
\text { nistração }\end{array}$ & Evolução & $\begin{array}{l}\text { Morte } \\
\text { após } \\
\text { adminis- } \\
\text { tração }\end{array}$ & $\begin{array}{c}\text { Recuperação } \\
\text { após } \\
\text { adminis- } \\
\text { tração }\end{array}$ \\
\hline Abrus & $2282^{a}$ & 100 & 24.7 .67 & 100 & 39 & 1,0 & Adoeceu +++ & $24 \mathrm{~h}$ & 11 dias & - & 12dias \\
\hline \multirow[t]{3}{*}{ precatorius } & “ & & 11.9.67 & 100 & 58 & 1,0 & Adoeceu +++ & $24 \mathrm{~h}$ & 5 dias & - & 6 dias \\
\hline & “ & & 25.9.67 & 100 & 63 & 1,0 & Não adoeceu & - & - & - & - \\
\hline & “ & 200 & 11.8 .68 & 200 & 15 & 1,0 & Adoeceu + & $48 \mathrm{~h}$ & 3 dias & - & 5 dias \\
\hline R. communis & “ & & 18.11 .68 & 400 & 0 & 2,0 & Não adoeceu & - & - & - & - \\
\hline Abrus & 2318 & 160 & 12.8 .68 & 16 & 1 & 0,1 & Adoeceu $+(+)$ & $24 \mathrm{~h}$ & 4 dias & - & 5 dias \\
\hline \multirow[t]{4}{*}{ precatorius } & “ & & 19.9.68 & 16 & 1 & 0,1 & Adoeceu + & $48 \mathrm{~h}$ & 2 dias & - & 4 dias \\
\hline & “ & & 14.10 .68 & 16 & 10 & 0,1 & Não adoeceu & - & - & - & - \\
\hline & " & & 18.11 .68 & 16 & 6 & 0,1 & Não adoeceu & - & - & - & - \\
\hline & & & 16.12 .68 & 160 & 113 & 10 & Não adoeceu & - & - & - & - \\
\hline R. communis & “ & 180 & 14.1 .69 & 360 & 0 & 2,0 & Não adoeceu & - & - & - & - \\
\hline Abrus & 2410 & 90 & 12.8 .68 & 10 & 0,1 & 0,11 & Não adoeceu & - & - & - & - \\
\hline \multirow{3}{*}{ precatorius } & “ & & 19.9.68 & 10 & 0 & 0,11 & Não adoeceu & - & - & - & - \\
\hline & “ & & 14.10 .68 & 10 & 0,5 & 0,11 & Não adoeceu & - & - & - & - \\
\hline & “ & & 18.11 .68 & 100 & 42 & 1,1 & Não adoeceu & - & - & - & - \\
\hline R. communis & “ & 108 & 16.12 .68 & 200 & 0 & 1,85 & Não adoeceu & - & - & - & - \\
\hline
\end{tabular}

a Pormenores sobre sintomas apresentados pelos bovinos constam em seguida:

\begin{tabular}{|c|c|c|c|c|c|c|c|c|c|}
\hline & Data & Fezes $^{\mathrm{c}}$ & $\begin{array}{l}\text { Diminuição } \\
\text { do apetite }^{\text {d }}\end{array}$ & Observações $^{\mathrm{e}}$ & & Data & Fezes $^{c}$ & $\begin{array}{l}\text { Diminuição } \\
\text { do apetite }^{\text {d }}\end{array}$ & Observações $^{\mathrm{e}}$ \\
\hline Bov.2282 & & & & & A. precatorius & 14.10 .68 & $\mathrm{~N}$ & . & \\
\hline A. precatorius & 24.7.67 & $\mathrm{N}$ & . & & $0,1 \mathrm{~g} / \mathrm{kg}$ & 15.10 .68 & $\mathrm{~N}$ & . & \\
\hline $\begin{array}{c}1,0 \mathrm{~g} / \mathrm{kg} \\
\mathrm{b}\end{array}$ & 25.7 .67 & Lfs & ++ & T40,5, apático, pêlos & Não adoeceu & 16.10 .68 & $\mathrm{~N}$ & . & \\
\hline Adoeceul ++ + & $\begin{array}{l}26.7 .67 \\
27.7 .67 \\
28.7 .67\end{array}$ & $\begin{array}{l}\text { Lfs } \\
\text { Lf } \\
\text { Lm }\end{array}$ & $\begin{array}{c}+++ \\
++ \\
+\end{array}$ & arreplacos & $\begin{array}{c}\text { A. precatorius } \\
0,1 \mathrm{~g} / \mathrm{kg} \\
\text { Não adoeceu }\end{array}$ & $\begin{array}{l}18.11 .68 \\
19.11 .68 \\
20.11 .68\end{array}$ & $\begin{array}{l}\mathrm{N} \\
\mathrm{N} \\
\mathrm{N}\end{array}$ & . & \\
\hline 30767 & P & + & & & A. precatorius & 161268 & $\mathrm{~N}$ & . & \\
\hline & 31.7 .67 & $\mathrm{~N}$ & . & & $1,0 \mathrm{~g} / \mathrm{kg}$ & 17.12 .68 & $\mathrm{~N}$ & . & \\
\hline & 1.8 .67 & $\mathrm{Pm}$ & ++ & & Não adoeceu & 18.12 .68 & $\mathrm{~N}$ & . & \\
\hline & $\begin{array}{l}2.8 .67 \\
3.8 .67\end{array}$ & $\begin{array}{c}\mathrm{L} \\
\mathrm{P} / \mathrm{L}\end{array}$ & $\begin{array}{l}+ \\
+\end{array}$ & & R. communis & 14.1 .69 & $\mathrm{~N}$ & . & \\
\hline & $\begin{array}{l}3.8 .61 \\
4.8 .67\end{array}$ & $\begin{array}{c}\mathrm{P} / \mathrm{L} \\
\mathrm{P}\end{array}$ & . & & $2,0 \mathrm{~g} / \mathrm{kg}$ & 15.1 .69 & $\mathrm{~N}$ & . & \\
\hline & 5.8 .67 & $\mathrm{~N}$ & . & Т 39,1 & Não adoeceu & 16.1 .69 & $\mathrm{~N}$ & . & \\
\hline A. precatorius & 11.9.67 & $\mathrm{N}$ & . & & Bov. 2410 & & & & \\
\hline $1,0 \mathrm{~g} / \mathrm{kg}$ & 12.9 .67 & Lmms & . & & A. precatorius & 12.8 .68 & $\mathrm{~N}$ & . & \\
\hline Adoeceu +++ & 13.9 .67 & Lms & . & T39,1 & $0,11 \mathrm{~g} / \mathrm{kg}$ & 13.8 .68 & $\mathrm{~N}$ & . & \\
\hline 14.9.67 & $\operatorname{Lms}(\mathrm{m})$ & ++ & & & Não adoeceu & 14.8 .68 & $\mathrm{~N}$ & . & \\
\hline & 15.9 .67 & $\operatorname{Lms}(\mathrm{m})$ & + & & A. precatorius & 19.9 .68 & $\mathrm{~N}$ & . & \\
\hline & 16.9 .67 & $P$ & . & & $0,11 \mathrm{~g} / \mathrm{kg}$ & 20.9 .68 & $\mathrm{~N}$ & . & \\
\hline & & & $\cdot$ & & Não adoeceu & 21.9 .68 & $\mathrm{~N}$ & . & Т 39,1 \\
\hline $\begin{array}{l}\text { A. precatorius } \\
\text { I,0 } 0 / / \mathrm{kg}\end{array}$ & $\begin{array}{l}25.9 .67 \\
26.9 .67\end{array}$ & $\begin{array}{l}\mathrm{N} \\
\mathrm{N}\end{array}$ & . & & A. precatorius & 14.10 .68 & $\mathrm{~N}$ & . & \\
\hline Não adoeceu & 27.9.67 & $\mathrm{N}$ & . & & $0,11 \mathrm{~g} / \mathrm{k}$ & 15.10 .68 & $\mathrm{~N}$ & . & \\
\hline A. precatorius & 12.8 .68 & $\mathrm{~N}$ & . & & Não adoeceu & 16.10 .68 & $\mathrm{~N}$ & . & \\
\hline $1,0 \mathrm{~g} / \mathrm{kg}$ & 13.8 .68 & $\mathrm{~N}$ & + & & A. precatorus & 18.11 .68 & $\mathrm{~N}$ & . & \\
\hline Adoeceu + & 14.8 .68 & $P$ & + & & $1,1 \mathrm{~g} / \mathrm{kg}$ & 19.11.68 & $\mathrm{N}$ & . & \\
\hline & 15.8 .68 & $\mathrm{~L}$ & ++ & & Não adoeceu & 20.11 .68 & $\mathrm{~N}$ & . & \\
\hline & 16.8.68 & $P$ & + & & R. communis & 16.12 .68 & $\mathrm{~N}$ & . & \\
\hline & 17.868 & $\mathrm{~N}$ & . & & $1,85 \mathrm{~g} / \mathrm{kg}$ & 17.12 .68 & $\mathrm{~N}$ & . & T39,0 \\
\hline R. communis & 18.11 .68 & $\mathrm{~N}$ & . & & Não adoeceu & 18.12 .68 & $\mathrm{~N}$ & . & \\
\hline $2,0 \mathrm{~g} / \mathrm{kg}$ & 19.11 .68 & $\mathrm{~N}$ & . & & & & & & \\
\hline Não adoeceu & 20.11 .68 & $\mathrm{~N}$ & . & & & & & & \\
\hline Bov.2318 & & & & & \multirow{12}{*}{\multicolumn{5}{|c|}{ 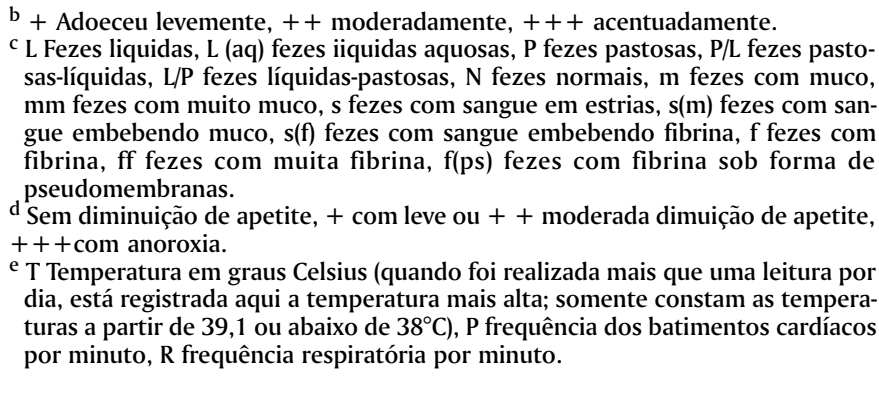 }} \\
\hline A. precatorius & 12.8 .68 & $\mathrm{~N}$ & . & & & & & & \\
\hline $\mathrm{O}, \mathrm{I} \mathrm{g} / \mathrm{kg}$ & 13.8 .68 & $\mathrm{Lm}$ & + & T 39,9 com tenesmo & & & & & \\
\hline Adoeceu $+(+)$ & 14.8 .68 & $\mathrm{Lm}$ & + & Т39,4 & & & & & \\
\hline & 15.8 .68 & $\mathrm{Lm}$ & + & & & & & & \\
\hline & $\begin{array}{l}16.8 .68 \\
17.8 .68\end{array}$ & $\begin{array}{l}\mathrm{L} \\
\mathrm{N}\end{array}$ & $\begin{array}{l}+ \\
+\end{array}$ & & & & & & \\
\hline & 18.8 .68 & $\mathrm{~N}$ & . & & & & & & \\
\hline A. precatorius & 19.9 .68 & $\mathrm{~N}$ & . & & & & & & \\
\hline $0,1 \mathrm{~g} / \mathrm{kg}$ & 20.9.68 & $\mathrm{N}$ & . & & & & & & \\
\hline Adueceu + & 21.9.68 & $\mathrm{Lm}$ & + & Т 39,4 & & & & & \\
\hline & 22.9 .68 & $P$ & . & & & & & & \\
\hline & 23.9.68 & $\mathrm{N}$ & . & & & & & & \\
\hline
\end{tabular}


Quad ro 2 . Imuniza ção de bovi nos através da administração das sementes i ntei ras de Ricinus communis e posterior administração de dose elevada única das sementes inteiras de Abrus precatorius (Resumo dos experimentos da Parte 2)

\begin{tabular}{|c|c|c|c|c|c|c|c|c|c|c|c|}
\hline \multirow[t]{3}{*}{ Sementes } & \multirow[t]{3}{*}{ Bovi no } & \multirow[t]{3}{*}{ Peso } & \multirow[t]{3}{*}{ Data } & \multicolumn{3}{|c|}{ QuantidadeDoseDesfecho } & \multirow[t]{3}{*}{ Inicio dos } & \multirow{3}{*}{$\begin{array}{l}\text { Evolução } \\
\text { sintomas } \\
\text { após admi- } \\
\text { nistração }\end{array}$} & \multirow[t]{3}{*}{ Morte } & \multirow{3}{*}{$\begin{array}{l}\text { Recuperação } \\
\text { após } \\
\text { adminis- } \\
\text { tração }\end{array}$} & \multirow{3}{*}{$\begin{array}{c}\text { após } \\
\text { adminis } \\
\text { tração }\end{array}$} \\
\hline & & & & $\begin{array}{c}\text { Admi- } \\
\text { nistra- } \\
\text { da }\end{array}$ & $\begin{array}{c}\text { Elimina- } \\
\text { da nas } \\
\text { fezes }\end{array}$ & & & & & & \\
\hline & & & & $\mathrm{g}$ & $\mathrm{g}$ & & & & & & \\
\hline Ricinus & $2415^{a}$ & 110 & 30.9 .68 & 110 & 0 & 1,0 & Adoeceu ++ & $24 \mathrm{~h}$ & 3 dias & - & 4 dias \\
\hline \multirow[t]{2}{*}{ communis } & “ & & 4.11 .68 & 220 & 0 & 2,0 & Adoeceu + & $24 \mathrm{~h}$ & 5 dias & - & 6 dias \\
\hline & “ & & 2.12 .68 & 220 & 0 & 2,0 & Não adoeceu & - & - & - & - \\
\hline A. precatorius & “ & 118 & 2.1 .69 & 110 & 35 & 0,93 & Adoeceu +++ & $48 \mathrm{~h}$ & 7 dias & - & 9 dias \\
\hline Ricinus & 2416 & 106 & 7.10 .68 & 212 & 0 & 2,0 & Adoeceu +++ & $24 \mathrm{~h}$ & 5 dias & - & 6 dias \\
\hline \multirow{2}{*}{ communis } & “ & & 18.11 .68 & 212 & 0 & 2,0 & Adoeceu ++ & $48 \mathrm{~h}$ & 2 dias & - & 4 dias \\
\hline & “ & 103 & 16.12 .68 & 206 & 0 & 2,0 & Não adoeceu & - & - & - & - \\
\hline A. precatorius & “ & 103 & 14.1 .69 & 110 & 53 & 1,06 & Adoeceu ++ & $48 \mathrm{~h}$ & 2 dias & - & 4 dias \\
\hline $\begin{array}{l}\text { Ricinus } \\
\text { communis }\end{array}$ & 2417 & 103 & 1.11 .68 & 300 & 0 & 2,91 & Morreu & $24 \mathrm{~h}$ & 19 dias & 20 dias & - \\
\hline
\end{tabular}

a Pommenores sobre sintomas apresentados pelos bovinos constam em seguida:

Data Fezes ${ }^{\mathrm{c}} \begin{aligned} & \text { Diminuição } \\ & \text { do apetite }^{\mathrm{d}}\end{aligned}$

Bov. 2415

R. communis

$1,0 \mathrm{~g} / \mathrm{kg} \quad-30.9 .68$

$\begin{array}{ll}\text { Adoeceu }++{ }^{\mathrm{b}} & 2.10 .68 \\ & 3.10 .68\end{array}$

4.10.68

R. communis 4.11 .68

$2,0 \mathrm{~g} / \mathrm{kg} \quad 5.11 .68$

Adoeceu $+\quad 6.11 .68$

7.11.68

8.11 .68

9.11 .68

10.11 .68

R. communis $\quad 2.12 .68$

$2,0 \mathrm{~g} / \mathrm{kg} \quad 3.12 .68$

Não adoeceu 4.12 .68

A. precatorius $\quad 2.1 .69$

$0,93 \mathrm{~g} / \mathrm{kg} \quad 3.1 .69$

Adoeceu $+++\quad 4.1 .69$

5.1.69

6.169

7.1.69

8.1.69

9.1 .69

10.1.69

11.1.69

Bov.2416

R. communis $\quad 7.10 .68$

$2,0 \mathrm{~g} / \mathrm{kg} \quad 8.10 .68$

Adoeceu +++9.10 .68$

10.10 .68
11.10 .68

11.10.68

13.10 .68

14.10 .68

R. communis 18.11 .68

$2,0 \mathrm{~g} / \mathrm{kg} \quad 19.11 .68$

Adoeceu + $+\quad 20.11 .68$

21.11 .68

22.11 .68

R. communis $\quad 16.12 .68$

$2,0 \mathrm{~g} / 1 \mathrm{xg} \quad 17.12 .68$

Não adoeceu 18.12 .68

\begin{tabular}{l}
19.12 .68 \\
\hline
\end{tabular}
Observações $^{\mathrm{e}}$

T 39,6

$++$

$++$

39,4

T39,1

en sem bracejos

Rúmen sem bracejos

Rúmen sem bracejos

T 39,5

T 40,3, abdômen volumoso

T 39,3

T 393

T 40,3

T 39,5

T 39,3

T 39,3

\begin{tabular}{|c|c|c|c|c|}
\hline & Data & Fezes $^{c}$ & $\begin{array}{l}\text { Diminuição } \\
\text { do apetite }^{\mathrm{d}}\end{array}$ & Observações $^{\mathrm{e}}$ \\
\hline A. precatorius & 14.1 .69 & $\mathrm{~N}$ & . & \\
\hline $1,0 \mathrm{~g} / \mathrm{kg}$ & 15.1 .69 & $\mathrm{~N}$ & . & T 39,2 \\
\hline \multirow[t]{3}{*}{ Adoeceu } & 16.1 .69 & $\mathrm{Lm}$ & . & T 39,6 \\
\hline & 17.1 .69 & $\mathrm{Lm}$ & . & \\
\hline & 18.1 .69 & $\mathrm{~N}$ & . & T 39,2 \\
\hline \multicolumn{5}{|l|}{ Bov.2417 } \\
\hline R. communis & 1.11 .68 & $\mathrm{~N}$ & . & \\
\hline $2,91 \mathrm{~g} / \mathrm{kg}$ & 2.11 .68 & $\mathrm{~L}$ & + & T 39,3 \\
\hline Morreu & 3.11 .68 & Ls & ++ & Т 39,2 \\
\hline \multirow{18}{*}{ (SAP 18661) } & 4.11 .68 & $\mathrm{~L}$ & ++ & \\
\hline & 5.11 .68 & $\mathrm{~L}$ & + & \\
\hline & 6.11 .68 & L & + & \\
\hline & 7.11 .68 & L & ++ & \\
\hline & 8.11 .68 & $P$ & ++ & Animal muito fraco \\
\hline & 9.11 .68 & L & ++ & “ \\
\hline & 10.11 .68 & $\mathrm{~L}$ & ++ & “ \\
\hline & 11.11 .68 & $P$ & ++ & “ \\
\hline & 12.11 .68 & $\mathrm{~N}$ & + & “ \\
\hline & 13.11 .68 & $\mathrm{~N}$ & . & T 37,7 \\
\hline & 14.11 .68 & $\mathrm{~N}$ & . & T 37,6 \\
\hline & 15.1168 & $\mathrm{~N}$ & . & \\
\hline & 16.11 .68 & $\mathrm{~N}$ & . & \\
\hline & 17.11 .68 & $\mathrm{~N}$ & . & \\
\hline & 18.11 .68 & $\mathrm{~N}$ & +++ & $\begin{array}{l}\text { Animal não consegue } \\
\text { mais ficar em pé }\end{array}$ \\
\hline & 19.11 .68 & $\mathrm{~N}$ & +++ & \\
\hline & 20.11 .68 & $\mathrm{~N}$ & +++ & \\
\hline & 21.11 .68 & $\mathrm{~N}$ & +++ & Morreu às $12 \mathrm{~h}$ \\
\hline
\end{tabular}

$\mathrm{b}+$ Adoeceu levemente, ++ moderadamente, +++ acentuadamente.

c L Fezes líquidas, L (aq) fezes líquidas aquosas, P fezes pastosas, P/L fezes pastosas-líquidas, $\mathrm{L} / \mathrm{P}$ fezes líquidas-pastosas, $\mathrm{N}$ fezes normais, $\mathrm{m}$ fezes com muco, $\mathrm{mm}$ fezes com muito muco, $\mathbf{s}$ fezes com sangue em estrias, $\mathbf{s}(\mathrm{m})$ fezes com sangue embebendo muco, $\mathbf{s}(\mathrm{f})$ fezes com sangue embebendo fibrina, $f$ fezes com fibrina, $\mathrm{ff}$ fezes com muita fibrina, $\mathrm{f}(\mathrm{ps})$ fezes com fibrina sob forma de pseudomembranas. d Sem diminuição de apetite, + com leve ou ++ moderada dimuição de apetite, +++ com anorexia.

eT Temperatura em graus Celsius (quando foi realizada mais que uma leitura por dia, está registrada aqui a temperatura mais alta; somente constam as temperaturas a partir de 39,1 ou abaixo de $38^{\circ} \mathrm{C}$ ), $\mathrm{P}$ frequência dos batimentos cardíacos por minuto, $\mathrm{R}$ frequência respiratória por minuto. 
Quadro 3. Imunização de bovinos através da administração das sementes moídas de Abrus precatorius e posterior administração de dose elevada única das sementes esmagadas de Ricinus communis (Resumo dos experimentos da Parte 3)

\begin{tabular}{|c|c|c|c|c|c|c|c|c|c|c|}
\hline Sementes & Bovino & Peso & Data & $\begin{array}{l}\text { Quantidade } \\
\text { adminis- } \\
\text { trada } \\
\mathrm{g}\end{array}$ & $\begin{array}{c}\text { Dose } \\
\mathrm{g} / \mathrm{kg}\end{array}$ & Desfecho & $\begin{array}{l}\text { Início dos } \\
\text { sintomas } \\
\text { após admi- } \\
\text { nistração }\end{array}$ & Evolução & $\begin{array}{l}\text { Morte } \\
\text { após } \\
\text { adminis- } \\
\text { tração }\end{array}$ & $\begin{array}{c}\text { Recuperação } \\
\text { após } \\
\text { adminis- } \\
\text { tração }\end{array}$ \\
\hline Abrus & $3559^{a}$ & 120 & 15.5 .74 & 30,0 & 0,25 & Adoeceu +++ & $24 \mathrm{~h}$ & 2 dias & - & 3 dias \\
\hline \multirow[t]{3}{*}{ precatorius } & " & 124 & 11.6 .74 & 62,0 & 0,5 & Adoeceu +++ & $14 \mathrm{~h}$ & 3 dias & - & 4 dias \\
\hline & $"$ & 125 & 9.7 .74 & 125,0 & 1,0 & Adoeceu + & $24 \mathrm{~h}$ & $1 \mathrm{dia}$ & - & 2 dias \\
\hline & $"$ & 133 & 6.8 .74 & 133,0 & 1,0 & Não adoeceu & - & - & - & - \\
\hline R. Communis & $"$ & 133 & 3.9.74 & 798,0 & 6,0 & Adoeceu+ & $48 \mathrm{~h}$ & $1 \mathrm{dia}$ & - & 3 dias \\
\hline Abrus & 3558 & 149 & 21.5.74 & 37,2 & 0,25 & Adoeceu +++ & $24 \mathrm{~h}$ & 5 dias & - & 6 dias \\
\hline \multirow[t]{3}{*}{ precatorius } & $"$ & 138 & 18.6 .74 & 69,0 & 0,5 & Adoeceu +++ & $24 \mathrm{~h}$ & 4 dias & - & 5 dias \\
\hline & $"$ & 135 & 16.7 .74 & 135,0 & 1,0 & Adoeceu + + & $12 \mathrm{~h}$ & 2 dias & - & 2 dias e meio \\
\hline & $"$ & 140 & 13.8 .74 & 140,0 & 1,0 & Adoeceu ++ & $24 \mathrm{~h}$ & $1 \mathrm{dia}$ & - & 2 dias \\
\hline R. communis & $"$ & 130 & 10.9 .74 & 780,0 & 6,0 & Adoeceu +++ & $36 \mathrm{~h}$ & 4 dias & - & 5 dias e meio \\
\hline Abrus & 3554 & 110 & 28.5 .74 & 27,5 & 0,25 & Adoeceu +++ & $24 \mathrm{~h}$ & 2 dias & - & 3 dias \\
\hline \multirow[t]{3}{*}{ precatorius } & $"$ & 117 & 25.6 .74 & 29,2 & 0,25 & Adoeceu +++ & $24 \mathrm{~h}$ & 3 dias & - & 4 dias \\
\hline & $"$ & 118 & 23.7.74 & 118,0 & 1,0 & Adoeceu + & $24 \mathrm{~h}$ & 2 dias & - & 3 dias \\
\hline & $"$ & 125 & 20.8 .74 & 125,0 & 1,0 & Não adoeceu & - & - & - & - \\
\hline R. communis & $"$ & 129 & 17.9 .74 & 774,0 & 6,0 & Adoeceu + & $55 \mathrm{~h}$ & 1 dia & - & 3 dias e meio \\
\hline
\end{tabular}

a Pormenores sobre sintomas apresentados pelos bovinos constam em seguida:

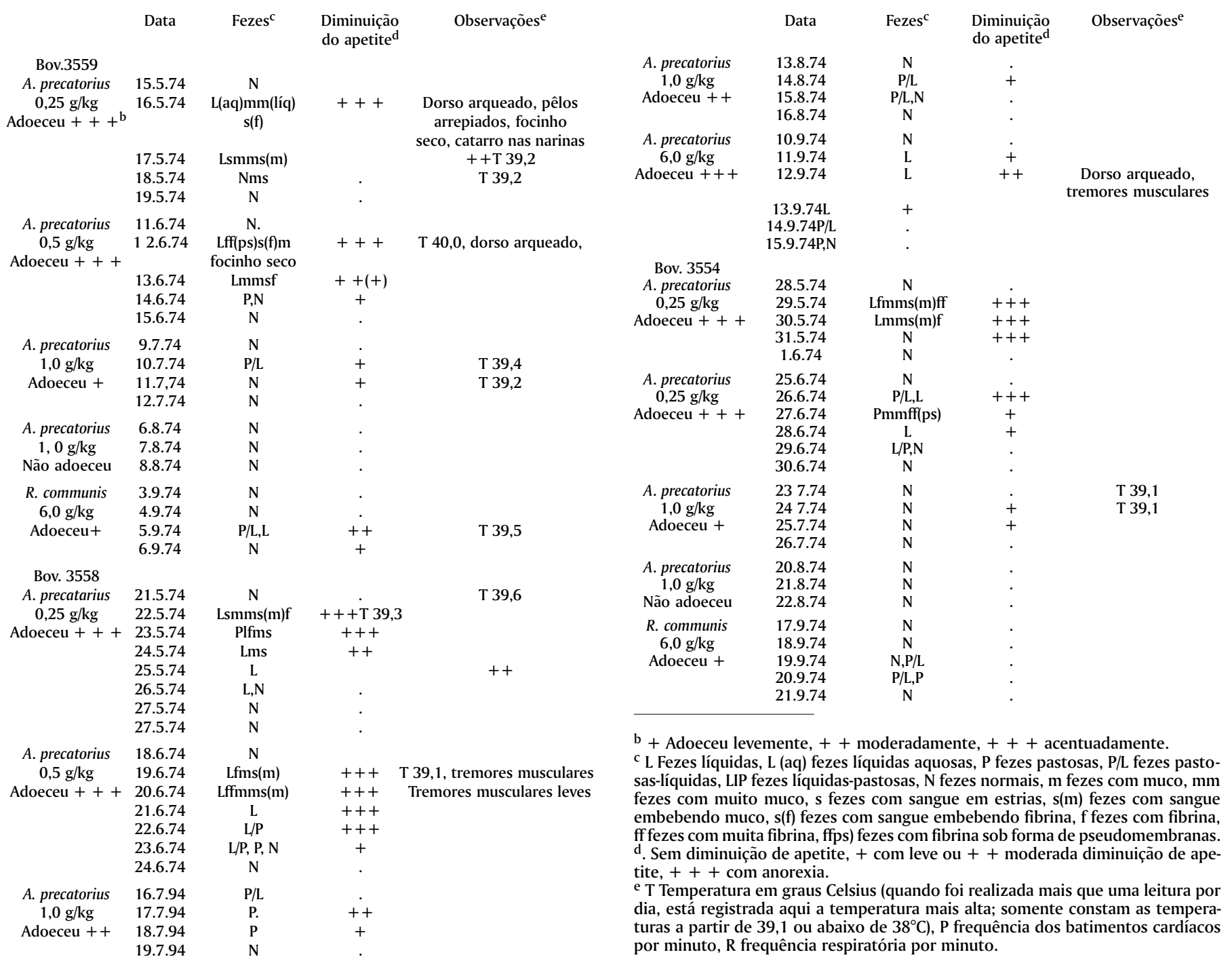


Quadro 4. Imunização de bovinos através da administração das sementes esmagadas de $R$. communis e posterior administração de dose elevada única das sementes moídas de Abrus precatorius. Posterior administração de dose elevada única das folhas sem talo frescas de $R$. communis e finalmente administração de dose elevada única do pericarpo de $R$. communis (Resumo dos experimentos da Parte 4 )

\begin{tabular}{|c|c|c|c|c|c|c|c|c|c|c|}
\hline Planta & Bovino & Peso & Data & $\begin{array}{c}\text { Quantidade } \\
\text { administrada } \\
\mathrm{g}\end{array}$ & $\begin{array}{l}\text { Dose } \\
\mathrm{g} / \mathrm{kg}\end{array}$ & Desfecho & $\begin{array}{l}\text { Início dos } \\
\text { sintomas } \\
\text { após admi- } \\
\text { nistração }\end{array}$ & Evolução & $\begin{array}{l}\text { Morte } \\
\text { após } \\
\text { adminis- } \\
\text { tração }\end{array}$ & $\begin{array}{c}\text { Recuperação } \\
\text { após } \\
\text { adminis- } \\
\text { tração } \\
\end{array}$ \\
\hline Ricinus & 3555a & 130 & 15.5 .74 & 130 & 1,0 & Adoeceu + & $24 \mathrm{~h}$ & 1 dia & - & 2 dias \\
\hline communis & “ & 135 & 11.6.74 & 405 & 3,0 & Adoeceu +++ & $24 \mathrm{~h}$ & 3 dias & - & 4 dias \\
\hline \multirow[t]{2}{*}{ (sementes) } & “ & 138 & 9.7 .74 & 828 & 6,0 & Adoeceu + & $24 \mathrm{~h}$ & 1 dia & - & 2 dias \\
\hline & “ & 145 & 6.8 .74 & 870 & 6,0 & Não adoeceu & - & - & - & - \\
\hline $\begin{array}{l}\text { A. precatorius } \\
\text { (sementes) }\end{array}$ & “ & 154 & 3.9.74 & 154 & 1,0 & Adoeceu +++ & $24 \mathrm{~h}$ & 3 dias & - & 4 dias \\
\hline $\begin{array}{l}R . \text { communis } \\
\text { (folhas) }\end{array}$ & “ & 153 & 25.9.74 & 4590 & 30,0 & Adoeceu +++ & 3h30min & $12 \mathrm{hl} 8 \mathrm{~min}$ & - & $15 \mathrm{~h} 48 \mathrm{~min}$ \\
\hline $\begin{array}{l}\text { R. communis } \\
\text { (pericarpo) }\end{array}$ & “ & 146 & 8.10 .74 & 730 & 5,0 & Adoeceu +++ & $1 \mathrm{~h} 40 \mathrm{~min}$ & $11 \mathrm{~h}$ & - & $12 \mathrm{~h} 40 \mathrm{~min}$ \\
\hline Ricinus & 3557 & 146 & 21.5 .74 & 292 & 2,0 & Adoeceu +++ & $24 \mathrm{~h}$ & 4dias & - & 5dias \\
\hline communis & “ & 148 & 18.6.74 & 444 & 3,0 & Não adoeceu & - & - & - & - \\
\hline \multirow[t]{2}{*}{ (sementes) } & “ & 148 & 16.7 .74 & 888 & 6,0 & Não adoeceu & - & - & - & - \\
\hline & “ & 157 & 13.8 .74 & 942 & 6,0 & Não adoeceu & - & - & - & - \\
\hline $\begin{array}{l}\text { A. precatorius } \\
\text { (sementes) }\end{array}$ & “ & 163 & 10.9 .74 & 163 & 1,0 & Adoeceu +++ & $24 \mathrm{~h}$ & 3dias & - & 4dias \\
\hline $\begin{array}{l}R . \text { communis } \\
\text { (folhas) }\end{array}$ & “ & 162 & 2.10 .74 & 2000 & 12,3 & Adoeceu ++ & $4 \mathrm{~h} 30 \mathrm{~min}$ & $7 \mathrm{~h} 15 \mathrm{~min}$ & - & 11h45min \\
\hline $\begin{array}{l}\text { R. communis } \\
\text { (pericarpo) }\end{array}$ & “ & 162 & 8.10 .74 & 810 & 5,0 & Morreu & $2 \mathrm{~h} 40 \mathrm{~min}$ & 4h $40 \mathrm{~min}$ & 7h $20 \mathrm{~min}$ & - \\
\hline Ricinus & 3556 & 132 & 28.5 .74 & 396 & 3,0 & Adoeceu +++ & $24 \mathrm{~h}$ & 5dias & - & 6dias \\
\hline communis & “ & 129 & 25.6 .74 & 645 & 5,0 & Adoeceu + + & $24 \mathrm{~h}$ & 2 dias & - & 3 dias \\
\hline \multirow[t]{2}{*}{ (sementes) } & “ & 134 & 23.7 .74 & 804 & 6,0 & Não adoeceu & - & - & - & - \\
\hline & & 148 & 20.8 .74 & 888 & 6,0 & Adoeceu + & $8 \mathrm{~h}$ & 1 dia & - & 1 dia e meio \\
\hline $\begin{array}{l}\text { A. precatorius } \\
\text { (sementes) }\end{array}$ & “ & 147 & 17.9.74 & 147 & 1,0 & Adoeceu + + + & $4 \mathrm{~h} 50 \mathrm{~min}$ & 3dias e meio & - & 3 dias e meio \\
\hline $\begin{array}{l}\text { R. communis } \\
\text { (folhas) }\end{array}$ & “ & 145 & 2.10 .74 & 4350 & 30,0 & Morreu & $2 \mathrm{~h} 20 \mathrm{~min}$ & 2h $06 \mathrm{~min}$ & 4h $26 \mathrm{~min}$ & - \\
\hline $\begin{array}{l}\text { Ricinus } \\
\text { communis } \\
\text { (sementes) }\end{array}$ & 3553 & 106 & 15.8 .73 & 636 & 6,0 & Morreu & $13 \mathrm{~h}$ & 4 dias & 4 dias e meio & - \\
\hline
\end{tabular}

a Pormenores sobre sintomas apresentados pelos bovinos constam em seguida:

Data $\quad$ Fezes $^{\mathrm{c}} \quad$ Diminuição $\begin{gathered}\text { Observações }^{\mathrm{e}} \\ \text { do apetite }^{\mathrm{d}}\end{gathered}$

Bov. 3555

\begin{tabular}{|c|c|c|c|c|}
\hline R. communis & 15.5 .74 & $\mathrm{~N}$ & . & \\
\hline $1,0 \mathrm{~g} / \mathrm{kg}$ & 16.5 .74 & $\mathrm{~N}$ & +++ & T 39,7 , focinho seco \\
\hline (sementes) & 17.5 .74 & $\mathrm{~N}$ & . & \\
\hline \multicolumn{5}{|l|}{ Adoeceu $+{ }^{b}$} \\
\hline R. communis & 11.6.74 & $\mathrm{N}$ & . & \\
\hline $3,0 \mathrm{~g} / \mathrm{kg}$ & 12.6 .74 & $\mathrm{~L}$ & +++ & T 39,7 , focinho seco \\
\hline (sementes) & 13.6 .74 & $\mathrm{~L}$ & +++ & \\
\hline \multirow[t]{2}{*}{ Adoeceu +++} & 14.6.74 & $\mathrm{P}$ & ++ & \\
\hline & 15.6 .74 & $\mathrm{~N}$ & . & \\
\hline R. communis & 9.7 .74 & $\mathrm{~N}$ & . & \\
\hline $6,0 \mathrm{~g} / \mathrm{kg}$ & 10.7 .74 & $\mathrm{~N}$ & + & \\
\hline (sementes) & 11.7.74 & $\mathrm{N}$ & . & T 39,6 \\
\hline \multicolumn{5}{|l|}{ Adoeceu + } \\
\hline R. communis & 6.8 .74 & $\mathrm{~N}$ & . & \\
\hline $6,0 \mathrm{~g} / \mathrm{kg}$ & 7.8 .74 & $\mathrm{~N}$ & . & \\
\hline (sementes) & 8.8 .74 & $\mathrm{~N}$ & . & \\
\hline
\end{tabular}

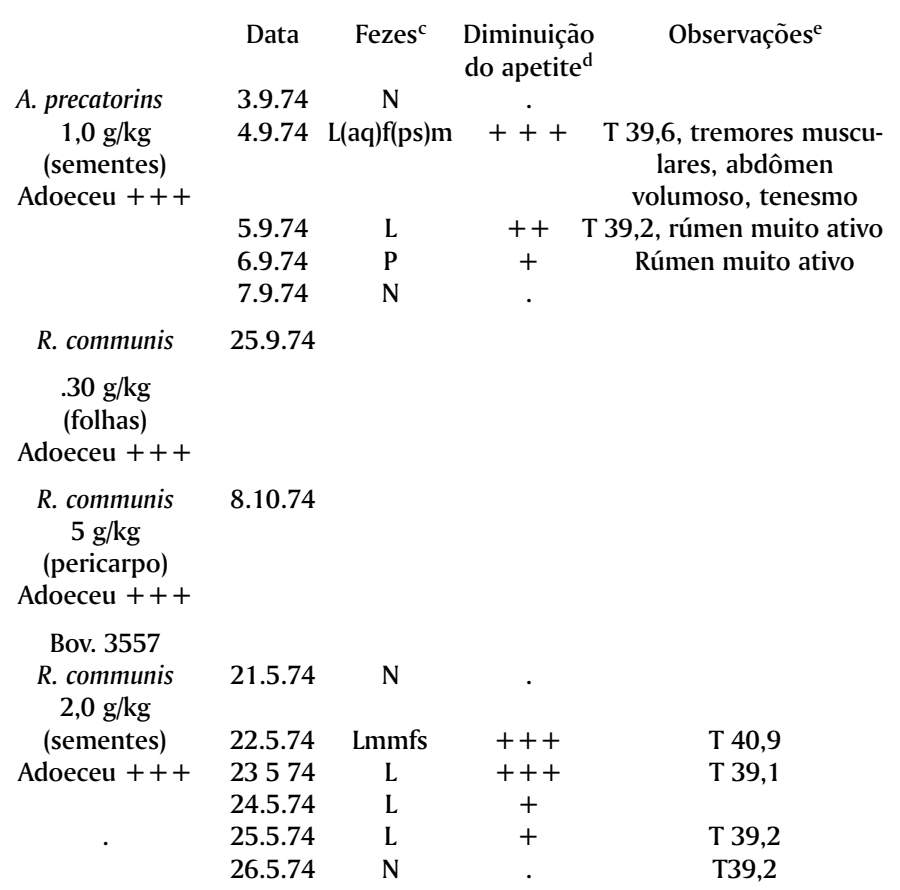

Pesq. Vet. Bras. 17(1):25-35, jan./mar. 1997 


\begin{tabular}{|c|c|c|c|c|c|c|c|c|c|}
\hline & Data & Fezes $^{c}$ & $\begin{array}{l}\text { Diminuição } \\
\text { do apetite }\end{array}$ & Observações ${ }^{e}$ & & Data & Fezes $^{\mathrm{c}}$ & $\begin{array}{l}\text { Diminuição } \\
\text { do apetite }^{\mathrm{d}}\end{array}$ & Observações ${ }^{e}$ \\
\hline Bov. 3557 & & & & & R. communis & 23.7.74 & $\mathrm{N}$ & . & T 39,2 \\
\hline R. cvmmunis & 18.6 .74 & $\mathrm{~N}$ & . & & $6,0 \mathrm{~g} / \mathrm{lcg}$ & 24.7.74 & $\mathrm{N}$ & + & \\
\hline $\begin{array}{l}\text { 3,0 g/kg } \\
\text { (sementes) }\end{array}$ & $\begin{array}{l}19.6 . / 4 \\
20.6 .74\end{array}$ & $\mathrm{~N}$ & . & Т 39,1 & (sementes) & 25.7 .74 & $\mathrm{~N}$ & & \\
\hline Não adoeceu & & & & ו, נת ו & Não adoeceu & & & & \\
\hline R. communis & 16.7.74 & $\mathrm{N}$ & . & & R. communis & 20.8 .74 & $\mathrm{P} / \mathrm{L}$ & ++ & \\
\hline $\begin{array}{c}\text { 6,0 /g/kg } \\
\text { (sementes) }\end{array}$ & $\begin{array}{l}17.7 .74 \\
18.74\end{array}$ & $\begin{array}{l}\mathrm{N} \\
\mathrm{N}\end{array}$ & · & Т 39,3 & $\begin{array}{l}6,0 \mathrm{~g} / \mathrm{lcg} \\
\text { (sementes) }\end{array}$ & $\begin{array}{l}21.8 .74 \\
22.8 .74\end{array}$ & $\begin{array}{c}\mathrm{P} / \mathrm{L}, \mathrm{N} \\
\mathrm{N}\end{array}$ & . & Т 39,1 \\
\hline Não adoeceu & 18.7.74 & & . & & Adoeceu + & & & & \\
\hline R. communis & 13.8 .74 & $\mathrm{~N}$ & . & & & & & & \\
\hline $6,0 \mathrm{~g} / \mathrm{kg}$ & 14.8 .74 & $\mathrm{~N}$ & . & T 39,1 & A. precatorias & 17.9.74 & $\mathrm{P} / \mathrm{Lff}(\mathrm{ps})$ & + & \\
\hline (sementes) & 15.8 .74 & $\mathrm{~N}$ & . & & $1,0 \mathrm{~g} / \mathrm{kg}$ & 18.9.74 & $\mathrm{L}(\mathrm{aq}) \mathrm{ms}$ & +++ & Т 39,3 \\
\hline Não adoeceu & & & & & (sementes) & 19.9.74 & $\mathrm{Lm}$ & +++ & \\
\hline A. precatorias & 10.9 .74 & $\mathrm{~N}$ & & Т 39,3 & Adoeceu +++ & 20.9.74 & $\mathrm{Lm}, \mathrm{P}$ & + & Т 39,2 \\
\hline $1,0 \mathrm{~g} / \mathrm{kg}$ & 11.9 .74 & $\mathrm{~L}(\mathrm{aq}) \mathrm{ms}$ & +++ & $\mathrm{T} 40,7$ & & 21.9 .74 & & & \\
\hline (sementes) & 12.9.74 & $\mathrm{L} / \mathrm{P}$ & & Т 39,1 & & & & & \\
\hline Adoeceu +++ & $\begin{array}{l}13.9 .74 \\
14.9 .74\end{array}$ & $\begin{array}{c}\mathrm{L} / \mathrm{Pm} \\
\mathrm{N}\end{array}$ & $\begin{array}{l}+ \\
.\end{array}$ & Т 39,1 & $\begin{array}{l}\text { R. communis } \\
30 \mathrm{~g} / \mathrm{kg} \\
\text { (folhas) }\end{array}$ & 2.10 .74 & & & \\
\hline $\begin{array}{l}\text { R. communis } \\
12,3 \mathrm{~g} / \mathrm{kg} \\
\text { (folhas) }\end{array}$ & 2.10 .74 & & & & $\begin{array}{c}\text { Morreu } \\
\text { (SAP 21684) }\end{array}$ & & & & \\
\hline Adoeceu ++ & & & & & Bov. 3553 & & & & \\
\hline R. communis & 8.10 .74 & & & & R. cammunis & 15.8 .74 & $\mathrm{~L}+++$ & & Abdomen volumoso \\
\hline $5 \mathrm{~g} / \mathrm{Icg}$ & & & & & $6,0 \mathrm{~g} / \mathrm{kg}$ & 16.8 .74 & $\mathrm{~L}(\mathrm{aq}) \mathrm{mmfs}(\mathrm{fls}$ & $s+++$ & \\
\hline $\begin{array}{c}\text { (pericarpo) } \\
\text { Morreu }\end{array}$ & & & & & $\begin{array}{l}\text { (sementes) } \\
\text { Morreu }\end{array}$ & 17.8 .74 & $\begin{array}{l}\mathrm{L}(\mathrm{aq}) \mathrm{sfms} \\
(\mathrm{m}) \text { flps) }\end{array}$ & +++ & $\begin{array}{c}\text { Com andar } \\
\text { cambaleante, apatia }\end{array}$ \\
\hline $\begin{array}{l}\text { (SAP 21690) } \\
\text { Bov. } 3556\end{array}$ & & & & & (SAP 21637/38) & 18.8 .74 & Lff(ps)s(ps)m & +++ & $\begin{array}{l}\text { T 37,5, superficie } \\
\text { do corpo fria }\end{array}$ \\
\hline R. communis & 28.5 .74 & $\mathrm{~N}$ & & & & 19.8 .74 & Lsmf & +++ & Morreu às $17: 14 \mathrm{~h}$ \\
\hline $3,0 \mathrm{~g} / \mathrm{kg}$ & 29.5 .74 & $\mathrm{~L}(\mathrm{aq}) \mathrm{ffms}(\mathrm{m})$ & +++ & $\mathrm{T} 40,2$, focinho seco & & & & & \\
\hline $\begin{array}{c}\text { (sementes) } \\
\text { Adoeceu }+++\end{array}$ & $\begin{array}{l}30.5 .74 \\
31.5 .74\end{array}$ & $\begin{array}{c}\mathrm{L}, \mathrm{L} / \mathrm{P} \\
\mathrm{Lf}\end{array}$ & $\begin{array}{c}++ \\
+++\end{array}$ & & \multirow{9}{*}{\multicolumn{5}{|c|}{$\begin{array}{l}\mathrm{b}+\text { Adoeceu levemente, }++ \text { moderadamente, }+++ \text { acentuadamente. } \\
\mathrm{c} \text { L Fezes líquidas, } \mathrm{L}(\mathrm{aq}) \text { fezes líquidas aquosas, } \mathrm{P} \text { fezes pastosas, } \mathrm{P} / \mathrm{L} \text { fezes } \\
\text { pasto-sas-líquidas, LIP fezes líquidas-pastosas, } \mathrm{N} \text { fezes normais, } \mathrm{m} \text { fezes com } \\
\text { muco, mm fezes com muito muco, s fezes com sangue em estrias, s(m) fezes } \\
\text { com sangue embebendo muco, } \mathrm{s}(\mathrm{f}) \text { fezes com sangue embebendo fibrina, } \mathrm{f} \\
\text { fezes com fibrina, ff fezes com muita fibrina, ffps) fezes com fibrina sob for- } \\
\text { ma de pseudomembranas. } \\
\text { d. Sem diminuição de apetite, }+ \text { com leve ou }++ \text { moderada diminuição de } \\
\text { apetite, }+++ \text { com anorexia. } \\
\text { e T Temperatura em graus Celsius (quando foi realizada mais que uma leitura } \\
\text { por dia, está registrada aqui a temperatura mais alta; somente constam as } \\
\text { temperaturas a partir de } 39,1 \text { ou abaixo de } 38^{\circ} \mathrm{C} \text { ), P frequência dos batimentos } \\
\text { cardíacos por minuto, } \mathrm{R} \text { frequência respiratória por minuto. }\end{array}$}} \\
\hline & 1.6 .74 & $\mathrm{~L}$ & ++ & $\begin{array}{l}\text { Globos oculares } \\
\text { retraidos levemente }\end{array}$ & & & & & \\
\hline & 2.6.74 & $\mathrm{L} / \mathrm{P}$ & + & & & & & & \\
\hline & 3.6.74 & $\mathrm{L} / \mathrm{P} \mathrm{ms}$ & . & & & & & & \\
\hline & 4.6 .74 & $\mathrm{~N}$ & . & & & & & & \\
\hline R. communis & 25.6 .74 & $\mathrm{~N}$ & . & & & & & & \\
\hline $5,0 \mathrm{~g} / \mathrm{kg}$ & 26.6 .74 & $\mathrm{~N}, \mathrm{P}, \mathrm{P} / \mathrm{L}, \mathrm{L}$ & . & & & & & & \\
\hline (sementes) & 27.6 .74 & $\mathrm{~L}, \mathrm{P}, \mathrm{P} / \mathrm{L}$ & + & & & & & & \\
\hline Adoeceu ++ & $\begin{array}{l}28.6 .74 \\
29.6 .74\end{array}$ & $\begin{array}{c}\mathrm{P}, \mathrm{N} \\
\mathrm{N}\end{array}$ & + & T39,1 & & & & & \\
\hline
\end{tabular}

As doses das sementes de $R$. communis que causaram a morte dos bovinos foi de $2,91 \mathrm{~g} / \mathrm{kg}$ (sementes inteiras) e $6 \mathrm{~g} /$ $\mathrm{kg}$ (sementes esmagadas). Fazendo-se uma comparação entre o efeito das diversas doses das sementes inteiras e esmagadas de $R$. communis, que provocaram sintomas de intoxicação sem causarem a morte dos bovinos, verifica-se que não houve diferença na sua ação tóxica (Quadro 5).

Já em relação às sementes de $A$. precatorius, verifica-se que há uma pequena diferença em sua ação tóxica a favor das sementes moídas. $\mathrm{O}$ único bovino que morreu, tinha ingerido $0,61 \mathrm{~g} / \mathrm{kg}$ (por sonda) das sementes moídas, enquanto que dois bovinos que ingeriram $1 \mathrm{~g} / \mathrm{kg}$ das sementes inteiras não morreram. (Quadro 5)

Os dados obtidos neste trabalho sobre início dos sintomas após a administração das sementes de $A$. precatorius e $R$. communis, evolução, prazos entre a administração das sementes e a morte ou recuperação constam no Quadro 6. Esses dados estão detalhados em relação aos experimentos com as sementes inteiras e moídas, e em relação aos experimentos em que os animais ingeriram as sementes pela primeira vez ou outras vezes. Os dados dos experimentos em que os animais, imunizados contra as sementes de uma das duas plantas, receberam as da outra, estão em separado. Também constam nesse Quadro, em separado, os dados obtidos anteriormente em relação à intoxicação experimental em bovinos pelas sementes de $A$. precatorius (Tokarnia et al. 1970). 
Quadro 5. Efeito tóxico da administração das sementes de Abrus precatorius e Ricinus communis em bovinos que antes nunca as ingeriram

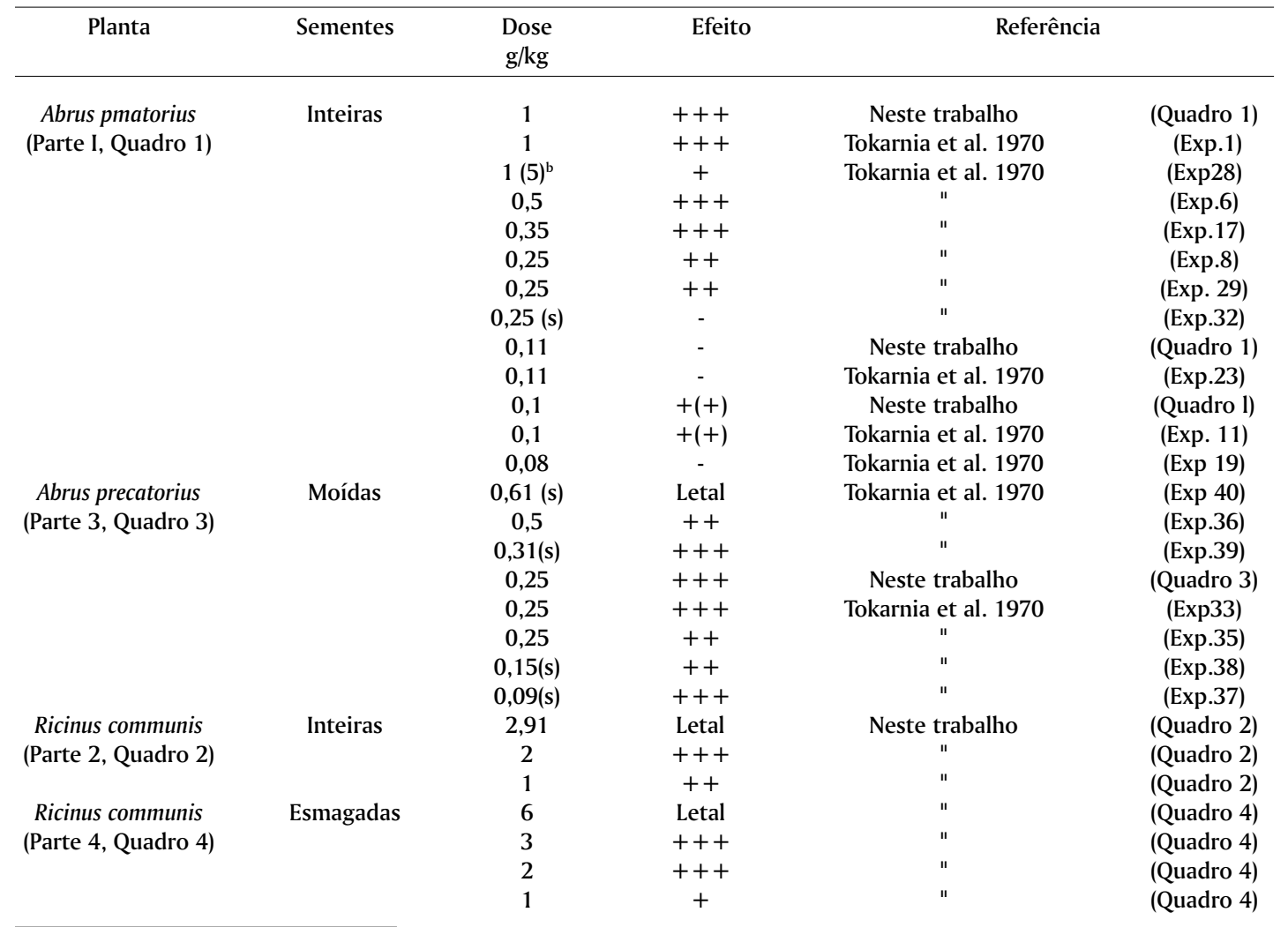

\footnotetext{
a Estão incluídos neste Quadro os dados obtidos anteriormente (Tokarnia et al. 1970) em relação à intoxicacão experimental em hovinos pelas sementes de $A$. precatorius.

${ }^{\mathrm{b}}(\mathrm{s})=$ administradas por sonda.
}

Resumindo, considerando-se em conjunto, os dados obtidos neste trabalho e os obtidos anteriormente em relação à intoxicação experimental em bovinos pelas sementes de $A$. precatorius (Tokarnia et al. 1970 ), mas levando em consideração somente os experimentos em que os animais receberam pela primeira vez as sementes de $A$. precatorius, os primeiros sintomas foram observados dentro de $\mathbf{2 4}$ horas após a administração das sementes, a evolução da intoxicação variou entre 2 e 11 dias e o prazo entre a administração das sementes e a recuperação foi de 3 a 12 dias (experimentos com as sementes inteiras ou moídas, administrações pela primeira vez). Nos experimentos com as sementes de $R$. communis os primeiros sintomas foram observados 13 a 24 horas após a administração das sementes, a evolução nos casos de morte foi de 3 e 19 dias, nos casos de recuperação foi de 1 a 5 dias e meio, a morte se deu entre 4 e 20 dias, e a recuperação entre 2 e 6 dias e meio, após a administração das sementes (experimentos com sementes inteiras ou moídas, administrações pela primeira vez). Os prazos dos experimentos em que os animais imunizados contra as sementes de uma das duas plantas recebiam as da outra, foram semelhantes.

\section{Quadro clinico}

Os sintomas nas intoxicações pelas sementes de Abrus precatorius (inteiras ou moídas) e Ricinus communis (inteiras ou esmagadas) foram semelhantes entre si, e foram essencialmente diarréia e diminuição de apetite até anorexia.

A diarréia se manifestava por fezes líquidas às vezes aquosas e aí eliminadas sob forma de esguicho, às vezes com mau cheiro, com presença de quantidades variáveis de muco e fibrina, esta última às vezes sob forma de pseudomembranas, presença de pequena quantidade de sangue sob forma de estrias, ou às vezes embebendo o muco ou a fibrina, raramente havia quantidades apreciáveis de muco ou de fibrina. Outras manifestações às vezes observadas foram abdômen inchado, pêlos arrepiados, focinho seco; temperatura elevada raras vezes foi constatada.

\section{Achados de necropsia e histopatológicos}

Durante os nossos experimentos somente morreram três bovinos, um durante os experimentos com as sementes de Abrus precatorius, e dois durante os experimentos com as sementes de Ricinus communis.

O único bovino que morreu durante os experimentos com as sementes de $A$. precatorius (Bov. 871), morreu 9 dias após a administração das sementes moídas por sonda, após ter mostrado diarréia durante 5 dias. Os achados de necropsia se resumiram em que a última parte do intestino delgado 
Quadro 6. Início dos sintomas após administração das sementes, evolução, prazos entre a administração das sementes e a morte ou recuperação

\begin{tabular}{|c|c|c|c|c|c|}
\hline Sementes & Administrações & $\begin{array}{c}\text { Inicio após } \\
\text { administração }\end{array}$ & Evolucão & $\begin{array}{l}\text { Morte após } \\
\text { administração }\end{array}$ & $\begin{array}{r}\text { Recuperação a } \\
\text { administraçã }\end{array}$ \\
\hline \multicolumn{6}{|c|}{ 1) Dados dos experimentos em que os bovinos receberam as sementes da mesma espécie, pela primeira vez e nas administrações seguintes } \\
\hline $\begin{array}{l}\text { A. precatorius (inteiras) } \\
\text { (Parte 1, Quadro 1) }\end{array}$ & $\begin{array}{l}1^{\mathrm{a}} \text { vez } \\
\text { Seguintes }\end{array}$ & $\begin{array}{c}24 \mathrm{~h} \\
24-48 \mathrm{~h}\end{array}$ & $\begin{array}{l}4-11 \text { dias } \\
2-5 \text { dias }\end{array}$ & - & $\begin{array}{l}5-12 \text { dias } \\
4-6 \text { dias }\end{array}$ \\
\hline $\begin{array}{l}\text { A. precatorius (moídas) } \\
\text { (Parte 3, Quadro 3) }\end{array}$ & $\begin{array}{l}1^{\mathrm{a}} \text { vez } \\
\text { Seguintes }\end{array}$ & $\begin{array}{c}24 \mathrm{~h} \\
12-24 \mathrm{~h}\end{array}$ & $\begin{array}{l}2-5 \text { dias } \\
1-4 \text { dias }\end{array}$ & - & $\begin{array}{l}3-6 \text { dias } \\
2-5 \text { dias }\end{array}$ \\
\hline $\begin{array}{l}\text { R. communis (inteiras) } \\
\text { (Parte 2, Quadro 2) }\end{array}$ & $\begin{array}{c}1^{\mathrm{a}} \text { vez } \\
\text { Seguintes }\end{array}$ & $\begin{array}{l}\mathrm{r}^{\mathrm{a}}: 24 \mathrm{~h} \\
\mathrm{~m}: 24 \mathrm{~h} \\
24-48 \mathrm{~h}\end{array}$ & $\begin{array}{l}3-5 \text { dias } \\
19 \text { dias } \\
2-5 \text { dias }\end{array}$ & $20 \overline{d i a s}_{-}^{-}$ & $\begin{array}{c}4-6 \text { dias } \\
- \\
4-6 \text { dias }\end{array}$ \\
\hline $\begin{array}{l}\text { R. communis (esmagadas) } \\
\text { (Parte 4, Quadro 4) }\end{array}$ & $\begin{array}{c}1^{\mathrm{a}} \text { vez } \\
\text { Seguintes }\end{array}$ & $\begin{array}{l}\mathrm{r}: 24 \mathrm{~h} \\
\mathrm{~m}: 13 \mathrm{~h} \\
8-24 \mathrm{~h}\end{array}$ & $\begin{array}{l}1-5 \text { dias } \\
4 \text { dias } \\
1-3 \text { dias }\end{array}$ & 4 dias e meio & $\begin{array}{c}2-6 \text { dias } \\
- \\
1-4 \text { dias }\end{array}$ \\
\hline
\end{tabular}

2) Dados dos experimentos em que os bovinos receberam as sementes da segunda espécie

A. precatorius- Os animais não adoeceram

R. communis (inteiras)

(Parte 1, Quadro 1)

\begin{tabular}{|c|c|c|c|c|c|}
\hline $\begin{array}{l}\text { A. precatorius- } \\
\text { R. communis (moídas e e } \\
\quad(\text { Parte } 3 \text {, Quadro 3) }\end{array}$ & $38-55 h$ & $1-4$ dias & - & 3-6 dias & \\
\hline $\begin{array}{l}\text { R. communis - } \\
\text { A. precatorius (inteiras) } \\
\quad(\text { Parte 2, Quadro 2) }\end{array}$ & & $48 \mathrm{~h}$ & $2-7$ & - & 4-9 dias \\
\hline $\begin{array}{l}\text { R. communis - } \\
\text { A. precatorius (esmagada } \\
\quad(\text { Parte 4, Quadro 4) }\end{array}$ & $5-24 h$ & 3 dias & - & 3-4 dias & \\
\hline \multicolumn{6}{|c|}{ 3) Dados do trabalho de Tokarnia et al. (1970) } \\
\hline A. precatorius (inteiras) & $\begin{array}{c}1^{\mathrm{a}} \text { vez } \\
\text { Seguintes }\end{array}$ & $\begin{array}{l}1-4 \text { dias } \\
2 \text { dias }\end{array}$ & $\begin{array}{l}2-7 \text { dias } \\
2-4 \text { dias }\end{array}$ & - & $\begin{array}{l}\text { 5-9 dias } \\
\text { 4-6 dias }\end{array}$ \\
\hline 4A. precatorius (moídas) & $\begin{array}{c}1^{\mathrm{a}} \text { vez } \\
\text { Seguintes }\end{array}$ & $\begin{array}{l}\text { r:1-2 dias } \\
\text { m: } 24 \mathrm{~h} \\
\text { aais não ad }\end{array}$ & $\begin{array}{c}2-6 \text { dias } \\
8 \text { dias }\end{array}$ & 9 dias & $\begin{array}{c}\text { 3-7dias } \\
-\end{array}$ \\
\hline
\end{tabular}

${ }^{\mathrm{a}} \mathrm{r}=$ relativo aos animais que se recuperaram, $\mathrm{m}=$ relativo aos animais que morreram.

tinha a mucosa vermelha e seu conteúdo estava mucoso e vermelho-escuro. Todo o sangue se apresentou com coloração vermelha-viva. Os exames histopatológicos (SAP 14748/ 49) revelaram congestão da mucosa e submucosa intestinal, com necrose das camadas superficiais da primeira, e no baço e em linfonodos, atrofia dos centros germinativos. (Tokarnia et al. 1970)

Um bovino (Bov. 2417) que morreu 20 dias após a administração por via oral da dose de $2,91 \mathrm{~g} / \mathrm{kg}$ das sementes inteiras de $R$. communis, teve enfraquecimento causado pela diarréia de 10 dias. Os achados de necropsia foram caquexia e atrofia gelatinosa de todas as gorduras. Os exames histopatológicos (SAP 18661) só revelaram no fígado edema difuso em grau moderado dos espaços de Disse e baço com leve congestão.

O outro bovino (Bov. 3553), que morreu pela administração da dose de $6 \mathrm{~g} / \mathrm{kg}$ das sementes esmagadas de $R$. communis, morreu 4 dias 9horas após a administração da planta, quan- do estava com diarréia acentuada. Os achados de necropsia foram rúmen com bastante alimentos, abomaso vazio, intestino delgado em algumas partes no início com bastante líquido esverdeado e com mucosa levemente avermelhada (congestão), ceco com conteúdo pastoso com muito mau cheiro, intestino grosso, especialmente os 2 últimos metros com mucosa levemente avermelhada (congestão) e sua parede levemente espessada (edema), só em uma pequena parte com conteúdo pastoso, o resto vazio, no reto presença de pequena quantidade de muco transparente. Os exames histopatológicos (SAP 21637-38) revelaram rúmen com edema moderado da própria, intestino grosso com leve congestão da parte superior da mucosa e moderado edema da submucosa, congestão moderada do pulmão e acentuada do baço.

\section{DISCUSSÃO}

Em nossos experimentos cinco bovinos imunizados contra a 
ação tóxica das sementes de Abrus precatorius não adoeceram ou somente levemente pela administração posterior das sementes de Ricinus communis em doses que em bovinos que antes nunca ingeriram sementes de $A$. precatorius ou $R$. communis causaram intoxicação de intensidade de grau moderado a acentuado ou até a morte, revelando que a imunidade conferida pela abrina neutralizou a ação da ricina. Um sexto bovino (Bov. 3558), que não ficou bem imunizado contra a ação tóxica das sementes de $A$. precatorius (Quadro 3), adoeceu em grau acentuado pela administração de dose elevada das sementes de $R$. communis.

Já dos cinco bovinos imunizados contra a ação tóxica das sementes de $R$. communis quatro adoeceram em grau acentuado, o quinto em grau moderado, pela administração posterior das sementes de $A$. precatorius em doses que em bovinos que antes nunca ingeriram sementes de $R$. communis ou $A$. precatorius causaram intoxicação de intensidade leve a acentuada. Desta maneira pode se concluir que bovinos imunizados contra a ação tóxica das sementes de $R$. communis não desenvolveram resistência contra a ação tóxica das sementes de $A$. precatorius.

Os nossos experimentos em bovinos só parcialmente confirmam as observações de Ehrlich (1891) e Clarke \& Humphreys (1971), de que as toxinas de $A$. precatorius e $R$. communis são diferentes do ponto de vista antigênico, não induzindo a imunidade cruzada. Nossos experimentos em bovinos indicam que administrações repetidas por via oral de sementes de $A$. precatorius conferem proteção contra doses elevadas das sementes de $R$. communis, porém administrações repetidas de sementes de $R$. communis não conferem proteção contra administrações posteriores de doses elevadas de se mentes de A. precatorius.

Uma explicação para esta divergência nos resultados poderia ser atribuída aos experimentos feitos. Nós usamos bovinos (poligástricos) e administramos as sementes por via oral, enquanto que Ehrlich (1891) e Clarke \& Humphreys (1971) fizeram os seus experimentos em roedores (monogástricos) e aplicaram as sementes ou as próprias toxinas por via parenteral.
Em relação ao quadro clinico-patalógico causado pelas sementes das duas plantas, é preciso ter cuidado ao analisar os dados da literatura, pois nem sempre fica bem claro, se as descrições, sobretudo dos achados de necropsia e das alterações histopalógicas, se referem às sementes ou toxinas administradas por via oral ou parenteral, e qual a espécie animal envolvida (Petri 1930, Steyn 1934, Volker 1950).

Os nossos experimentos também demonstraram que bovinos imunizados com as sementes de $R$. communis não são resistentes contra a ação tóxica das folhas e do pericarpo do próprio $R$. communis, porque o principio tóxico destas partes é o alcalóide ricinina.

O nosso trabalho experimental em bovinos teve como finalidade principal verificar a possibilidade da existência de imunidade cruzada entre as sementes de $A$. precatorius e $R$. communis. No decorrer dos experimentos foi possível obter grande número de dados sobre o quadro clínico da intoxicação pelas sementes das duas plantas. Porém em relação aos achados de necropsia e a histopatologia os nossos dados são escassos, pois morreram somente dois bovinos devido a intoxicação pelas sementes de $R$. communis e um bovino pelas sementes de $A$. precatorius.

\section{REFERENCIAS}

Clarke E.G.C. \& Humphreys DJ.1971. The detection of abrin. J. Forensic Scient. Society 11:109-112.

Döbereiner J., Tokarnia C. H. \& Canella C.F.C. 1981. Experimental poisoning of cattie by the pericarp of the fruit of Ricinus communis. Pesq. Vet. Bras. 1 (3):95-97.

Ehrlich R 1891. Experimentelle Untersuchungen über Immunität. II. Ueber Abrin. Dtsch. Med. Wschr. No. 44:1218-1219.

Petri E.1930. Pathologische Anatomie und Histologie der Vergiftungen. Verlag J. Springer, Berlin.

Tokarnia C.H., Döbereiner J. \& Monteiro M.C. 1970. Intoxicação experimental em bovinos pela semente de Abrus pecatorius. Pesq. Agropec. Bras. 5:441452.

Tokarnia C.H., Döbereiner J. \& Canella C.F.C. 1975. Intoxicação experimental em bovinos pelas folhas de Ricinus communis. Pesq. Agropec. Bras., Sér. Vet. 10:1-7. 